\title{
ТЕХНИКО-ЭКОНОМИЧЕСКОЕ ОБОСНОВАНИЕ ТЕПЛОСНАБЖЕНИЯ РАЙОНА ГОРОДА НА ОСНОВЕ ДЕЦЕНТРАЛИЗОВАННЫХ И ЦЕНТРАЛИЗОВАННЫХ ИСТОЧНИКОВ ЭНЕРГИИ
}

\author{
(C) 2020 Чекмарев Сергей Юрьевич \\ кандидат экономических наук, \\ заведующий кафедрой «Экономика и организация управления в энергетике» \\ Петербургский энергетический институт повышения квалификации, Россия, Санкт-Петербург \\ E-mail: serj.chekmarev@yandex.ru

\section{(c) 2020 Лягалов Никита Александрович} \\ магистр \\ Санкт-Петербургский политехнический университет Петра Великого, Россия, Санкт-Петербург \\ E-mail: nikita.lyagalov@yandex.ru

\section{(c) 2020 Малинина Татьяна Всеволодовна} \\ кандидат экономических наук, доцент \\ Санкт-Петербургский политехнический университет Петра Великого, Россия, Санкт-Петербург \\ E-mail:t_malinina@mail.ru
}

Рассмотрены принципы и основы функционирования систем теплоснабжения. Выполнен анализ текущего состояния теплоснабжения и объектов перспективного строительства. Проведена экономическая и инвестиционная оценка прогнозируемых вариантов теплоснабжения на основе централизованной и децентрализованной систем теплоснабжения. Проанализированы варианты предполагаемого строительства объектов теплоснабжения и оценена перспективность инвестиций.

Ключевые слова: система теплоснабжения, централизованное теплоснабжение, децентрализованное теплоснабжение, тепловая сеть, источник тепловой энергии.

В условиях Российской Федерации теплоснабжение является одной из важнейших экономически и социально-значимых систем. Около трети используемых в стране первичных топливно-энергетических ресурсов идут на нужды теплоснабжения. По обороту теплоснабжение составляет 2,5\% ВВП РФ, что исчисляется 1,5 трлн. руб. и достигает более 50\% в платеже граждан за жилищно-коммунальные услуги [1].

На сегодняшний день состояние отрасли неудовлетворительно. Отпуск в системах централизованного теплоснабжения за последние 30 лет упал почти в 2 раза, наблюдается низкая загрузка ТЭЦ и котельных, темпы замены теплосетей отстают от темпов их износа. Доля теплосетей общего пользования, нуждающихся в замене, составляет 28,9\%, 45\% магистральных тепловых сетей отработали нормативный срок эксплуатации [2]. Такая ситуация сохраняется уже продолжительное время, в частности литературе [3] отмечалось, что в 2005 году около 50\% объектов теплоснабжения и инженерных сетей требовали замены. Объем заменяемых тепловых сетей в настоящее время составляет $2 \%$ в год, что не позволяет снизить динамику старения тепловых сетей: инвестиции в сектор распределения тепловой энергии в 2018 году в России составили 36\% в номинальном выражении от объема инвестированных средств 2014 года.

Потери в тепловых сетях составляют до 30\% выработки тепла [2], а по некоторым источникам величина потерь доходит до 55-60\% [3]. Это приводит к снижению КПД, а в сочетании с физически и морально устаревшими основными средствами теплогенерирующих предприятий к росту издержек, и, соответственно, к увеличению себестоимости отпускаемого тепла и необходимости роста тарифов.

Несмотря на то, что отпускная цена на тепло от ТЭС ниже, чем от котельных на всей территории России в 2018 г. (1028 руб./Гкал на ТЭС и 1775 руб./Гкал на котельных), низкая эффективность сферы передачи тепла приводит к значительным розничным ценам на теплоэнергию и росту количества децентрализованных источников тепла. 
Согласно данным [2], основным направлением развития теплоснабжающих систем в РФ является увеличение количества автономных котельных мощностью до 3 Гкал/ч, отпуск тепла котельными вырос с 2014 по 2018 год на 5\%, причем на 2018 год доля децентрализованных источников (котельных) по мощности составляет $69 \%$, ТЭЦ - $31 \%$.

Проблемы централизованного теплоснабжения делают актуальным вопрос рассмотрения альтернативных вариантов теплоснабжения, в качестве которых могут рассматриваться системы децентрализованного теплоснабжения. Современные автономные теплогенераторы имеют КПД, сопоставимые с КПД котельных или выше. Кроме того, использование децентрализованных систем теплоснабжения позволяет практически полностью исключить тепловые потери при передачи энергии в силу близкого расположения объектов генерации и потребления.

Наиболее сложным является выбор системы теплоснабжения в городах с уже сложившейся системой централизованного теплоснабжения.

В силу необходимости масштабной реконструкции основных средств теплогенерирующих объектов, с одной стороны, и привлекательностью децентрализованных источников тепловой энергии, с другой - возникает вопрос выбора оптимального варианта теплоснабжения города.

Для сравнения эффективности централизованного и децентрализованного теплоснабжения был выбран район города Кронштадт, где требовалось провести реконструкцию существующей системы теплоснабжения с учетом перспектив увеличения тепловой нагрузки района.

В процессе исследования были поставлены следующие цели:

1. Изучение характеристик различных систем теплоснабжения, изучение существующей системы теплоснабжения.

2. Проведение технико-экономического анализа развития централизованной и децентрализованной систем теплоснабжения.

3. Обоснование выбора оптимального варианта системы теплоснабжения.

В результате анализа данных о функционирующей системе теплоснабжения [6] были выявлены недостатки, свойственные как существующей системе района, так и системе централизованного теплоснабжения в целом, а именно:

1. Невысокий коэффициент использования установленной мощности, составляющий $23 \%$ для котельной № 1 и 18,5\% для котельной № 2 .

2. Наличие неиспользуемых мощностей, требующих реконструкции, а именно двух паровых котлов ДКВр-20/13 мощностью 15,7 Гкал/ч на котельной № 1.

3. Высокий процент теплопроводов, исчерпавших свой эксплуатационный ресурс, составляющий $28,3 \%$ от общей протяженности трубопроводов.

4. Высокий показатель потерь тепловой мощности в теплосетях, существенно превышающий нормативный.

Проведенный анализ планов ввода объектов теплоснабжения нового строительства показал наличие нагрузки, не обеспеченной мощностью.

В качестве исходных данных использовались сведения о существующей системе теплоснабжения района, данные о тепловых потерях в теплосетях, баланс мощности и сведения о перспективной нагрузке, представленные в схеме теплоснабжения [4].

Для оценки стоимости строительства и реконструкции котельных, а также разделения затрат по этапам строительства использовался результат совместной работы АО «Газпром промгаз» и ФБГУ ВО «Санкт-Петербургский государственный экономический университет» в рамках проекта «Разработка методического обеспечения обоснования стоимости реализации адресных перечней мероприятий схемы теплоснабжения Санкт-Петербурга» [4].

Также использовались исходные данные ведущих теплоснабжающих организаций СанктПетербурга по проектам строительства и реконструкции систем теплоснабжения и данные проектов, выполненных АО «Газпром промгаз», по технико-экономическому обоснованию реконструкции и развития систем теплоснабжения в регионах РФ со сходными природными и климатическими условиями [4].

Для обеспечения новых потребителей тепловой энергией были рассмотрены два варианта проекта:

Проект 1 (централизованное теплоснабжение) - с присоединением участков к действующей теплосети со строительством подводящего трубопровода, поэтапным выводом из эксплуатации и демонтажем паровых котлов 
ДКВр-20/13, и монтажом на освободившемся месте водогрейных котлов общей мощностью 40 Гкал/ч для обеспечения нагрузки. Горизонт планирования составляет 25 лет. Потери в теплосети взяты, исходя из текущих данных, и составляют $10 \%$ от отпускаемой тепловой мощности.

Проект 2 (децентрализованное теплоснабжение) - со строительством локальных источников тепловой мощности без присоединения к централизованной системе теплоснабжения. В силу близкого расположения потребителей мощности от теплогенерирующего объекта данный вариант теплоснабжения можно считать примером децентрализованного теплоснабжения. Основным оборудованием котельной были выбраны 3 котла КВ-ГМ-10 мощностью 10 Гкал/ч каждый. Общая установленная мощность котельной составила 30 Гкал/ч. При рассмотрении этого проекта не учитывались вложения в тепловые сети, так как котельная и потребители расположены в непосредственной близости друг от друга. При данной близости объектов теплогенерации и потребителей тепловой энергии сооружение магистральных теплосетей не требуется, а прокладкой внутриквартальных трубопроводов можно пренебречь в силу малой протяженности и низких удельных затрат. Горизонт планирования составляет 25 лет. Потери мощности при передаче принимались в размере $5 \%$.

Для определения целесообразности инвестиций и выбора оптимального варианты централизованного и децентрализованного энергоснабжения были оценены показатели экономической эффективности (см. таблицу 1) [6].

Как видно из сравнительной таблицы 1, Проект 1 имеет незначительное предпочтение по сравнению с Проектом 2:
1) капиталовложения Проекта 1 меньше на 34,8 тыс. руб. или $8,7 \%$, несмотря на дополнительные капвложения в строительство магистральных теплосетей;

2) себестоимость производства тепловой энергии у Проекта 1 ниже на 10 руб./Гкал или 0,6\%. Подобную разницу можно считать незначительной, лежащей в пределах погрешности;

3) чистый дисконтированный доход за рассматриваемый период у Проекта 1 больше на 33077 тыс. руб. или на 21\%;

4) период окупаемости Проекта 1 меньше за счет меньших капиталовложений и более высоких показателей прибыли.

Результаты сравнения вариантов показали примерную равноценность рассмотренных проектов по всем относительным показателям, однако ЧДД Проекта 1 (централизованное теплоснабжение) оказался выше, следовательно, на первый взгляд инвестиции в Проект 1 более оправданы.

Для более детальной оценки экономической эффективности был проведен анализ чувствительности в условиях отклонения реальных показателей от прогнозных. В качестве ключевого параметра при анализе чувствительности был выбран показатель нормы потерь в теплосетях. Были рассмотрены варианты с нормой тепловых потерь 15\%, 20\%, 25\% и 30\%. Показатели экономической эффективности для Проекта 1 при изменении теплопотерь приведены в табл.2. Сравнительная оценка вариантов централизованного и децентрализованного теплоснабжения приведена на рис.1.

На основании результатов расчетов можно сделать вывод: с ростом потерь в теплосетях существенно снижается экономическая эффективность Проекта 1 - проекта централизован-

Таблица 1. Сравнение инвестиционных проектов централизованного и децентрализованного теплоснабжения

\begin{tabular}{|c|c|c|c|c|}
\hline \multirow{2}{*}{ Наименование показателя } & \multirow{2}{*}{ Обозначение } & \multirow{2}{*}{$\begin{array}{c}\text { Единицы } \\
\text { измерения }\end{array}$} & \multicolumn{2}{|c|}{ Значение } \\
\hline & & & Проект 1 & Проект 2 \\
\hline Стоимость реализации проекта & $\mathrm{K}$ & тыс. руб. & 401,4 & 436,2 \\
\hline Себестоимость тепловой энергии & $\mathrm{C}$ & руб./Гкал & 1570 & 1580 \\
\hline Чистый дисконтированный доход & ЧДД & тыс.руб. & 156861,2 & 123784,2 \\
\hline Индекс доходности & ИД & & 1,43 & 1,31 \\
\hline Внутренняя норма доходности & ВНД & $\%$ & 17,97 & 16,3 \\
\hline Средняя чистая прибыль & Пч.ср. & тыс.руб./год & 57786,36 & 56944,25 \\
\hline Простая норма рентабельности & $\mathrm{R}$ & & 0,14 & 0,13 \\
\hline Срок окупаемости & Tok & лет & 7 & 7,66 \\
\hline
\end{tabular}


Таблица 2. Анализ влияния теплопотерь на доходность Проекта 1

\begin{tabular}{|l|c|c|c|c|c|c|}
\hline \multicolumn{2}{|c|}{ Норма теплопотерь } & 10 & 15 & 20 & 25 & 30 \\
\hline Себестоимость тепловой энергии & руб./Гал & 1570 & 1620 & 1680 & 1740 & 1820 \\
\hline $\begin{array}{l}\text { Чистый дисконтированный } \\
\text { денежный доход }\end{array}$ & тыс.руб. & 156861,2 & 134122,5 & 108541,4 & 79549,5 & 46416 \\
\hline Индекс доходности & & 1,43 & 1,37 & 1,29 & 1,22 & 1,13 \\
\hline Внутренняя норма доходности & $\%$ & 17,97 & 17,13 & 16,17 & 15,08 & 13,8 \\
\hline Средняя чистая прибыль & $\begin{array}{c}\text { тыс.руб./ } \\
\text { год }\end{array}$ & 57786,36 & 54702,81 & 51233,8 & 47302,31 & 42810 \\
\hline Простая норма рентабельности & & 0,14 & 0,14 & 0,13 & 0,12 & 0,11 \\
\hline Срок окупаемости & лет & 7 & 7,35 & 7,83 & 8,5 & 9,4 \\
\hline
\end{tabular}

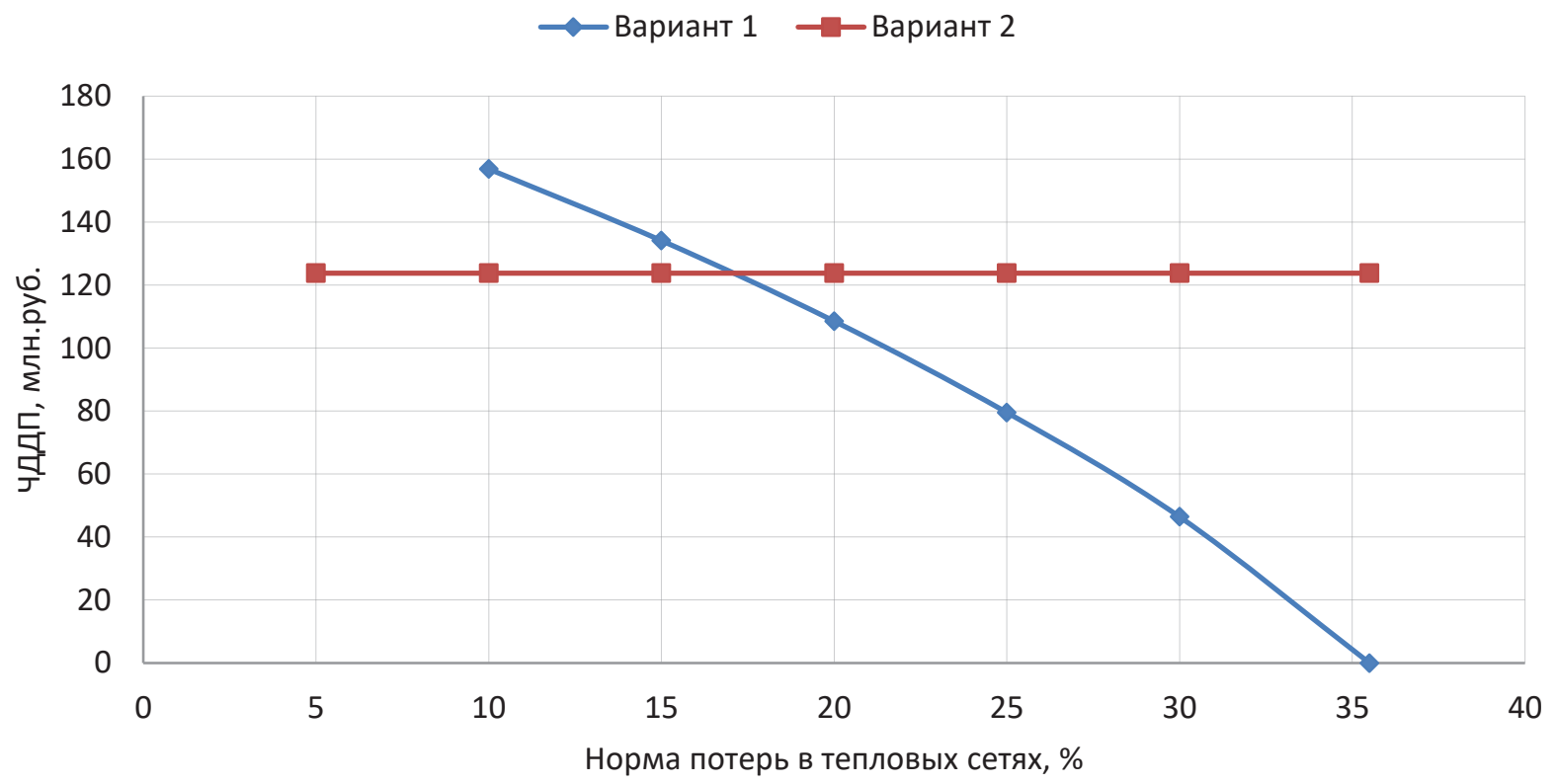

Рисунок 1. Зависимость ЧДД проектов от потерь в сетях

ной системы теплоснабжения.

График зависимости ЧДД от нормы потерь в тепловых сетях (рис. 1) показывает, что несмотря на то, что Проект 1 остается доходным при значении величины тепловых потерь в сетях, доходящей до $35 \%$, он начинает проигрывать в эффективности Проекту 2 после превышения величины потерь в теплосетях, равной $17 \%$. Необходимо отметить, что по оценкам некоторых специалистов [2], эта величина ниже средних потерь в существующих тепловых сетях.

Из этого следует, что эффективность децентрализованного теплоснабжения по сравнению с централизованным повышается с ростом значения потерь в теплосетях. Негативный эффект от увеличения потерь энергии в тепловых сетях свыше 15-20\% перекрывает даже экономию, получаемую при предпочтении реконструкции (централизованное теплоснабжение) новому строительству (децентрализованное теплоснабжение).

Сравнение вариантов теплоснабжения района города показало, что при текущем значении тепловых потерь в сети на уровне 10\% предпочтительнее реконструкция действующей котельной, предусмотренная Проектом 1 , то есть вариант централизованного теплоснабжения. Однако, учитывая прогнозную динамику состояния теплосети (значительный рост тепловых потерь), более перспективным является вариант строительства нового источника тепловой энергии, предложенного в Проекте 2 , то есть децентрализованное теплоснабжение.

Таким образом, на основании проведенного исследования можно сделать вывод, что при низких значениях тепловых потерь в сетях 
экономическая эффективность проектов реконструкции котельных, действующих в рамках централизованной системы теплоснабжения, выше, чем проектов строительства новых локальных котельных - децентрализованное теплоснабжение. Соответственно, если теплосеть, обслуживающая котельную, не изношена и функционирует с достаточно высоким КПД (85\% и более), а также темпы модернизации не превышают темпы износа, то инвестиции в реконструкцию котельных (централизованное теплоснабжение) более целесообразны. Если же в составе теплосети высока доля трубопроводов, исчерпавших свой эксплуатационный ресурс, и значение нормы потерь в тепловых сетях превышает $17 \%$, то предпочтительным является децентрализованное теплоснабжение - строительство новых источников тепловой мощности, расположенных рядом с потребителями. Представляется, что при существующем уровне износа тепловых сетей и низких объемах их замены в перспективе приоритет следует отдать децентрализованной системе теплоснабжения.

\section{Библиографический список}

1. Доклад Министра энергетики Российской Федерации А.В.Новака на совещании у Председателя Правительства Российской Федерации Д.А. Медведева о мерах, направленных на повышение темпов газификации в Российской Федерации URL: https://minenergo.gov.ru/.

2. Информационно-аналитический доклад «Теплоэнергетика и централизованное теплоснабжение России в 2014-2018 годах». Москва, 2020. URL: https://minenergo.gov.ru/system/download-pdf/17737/116638.

3. Асланян Г.С., Фаворский О.Н. Экономические механизмы повышения эффективности предоставления коммунальных услуг по энерго- и водоснабжению. Теплоэнергетика, 2005, № 2. с.24-30.

4. Схема теплоснабжения Санкт-Петербурга до 2031 года (актуализация на 2017 г.) Утверждена приказом № 1330 Министерства энергетики Российской Федерации от 16.12.2016 г. URL: http://gov.spb.ru.

5. Тузников, М.А. Методические указания для выполнения курсового проекта по дисциплине «Экономика инвестиционной деятельности» / М. А. Тузников. Санкт-Петербург, 2015. 46с.

6. Бугаева T.M., Спицкая М.В. Перспективы развития системы теплоснабжения Приморского района г. СанктПетербурга. В сборнике: Эффективная энергетика - 2014 Труды Всероссийской научно-практической конференции. 2015. С. 316-328.

7. Барсков В.В., Белостоцкая А.А., Забелин Б. Ф., Конников Е.А. Актуальные вопросы производственного менеджмента в практической деятельности промышленного предприятия // Казань, 2017.

8. Галиева Д.А., Иванова Е.Г., Конников Е.А., Конникова О.А. Принципы формирования эффективных проектов в области повышения энергоэффективности деятельности предприятия // Экономические науки. 2020. № 188 . С. $37-42$.

9. Кичигин О.Э., Родионов Д.Г. Институциональный аспект формирования стратегических ориентиров государственной энергетической политики на региональном уровне при реализации стратегии национальной экономической безопасности // Экономика и предпринимательство. 2017. № 10-2 (87). С. 394-399.

10. Скворцова И.В., Конников Е. А., Курбанбаева А.Ф. Сравнительный технико-экономический анализ инновационной и традиционных систем теплоснабжения индивидуального жилищного строительства // Экономика и предпринимательство. 2016. № 4-2 (69). С. 307-311.

11. Родионов Д.Г., Владимирова И.Г., Семенова О.С. Экономические аспекты утилизации твердых бытовых отходов в городком хозяйстве мегаполисов // Научно-технические ведомости Санкт-Петербургского государственного политехнического университета. Экономические науки. 2008. № 1 (53). С. 75-80. 